\title{
Dietary Non-Drug Feed Additive as an Alternative for Antibiotic Growth Promoters for Broilers During a Necrotic Enteritis Challenge
}

\author{
Ali Calik ${ }^{1,2}$, Islam I. Omara ${ }^{1,3}$, Mallory B. White ${ }^{1}$, Nicholas P. Evans ${ }^{4}$, T. Peter Karnezos ${ }^{4}$ \\ and Rami A. Dalloul ${ }^{1, *}$ \\ 1 Avian Immunobiology Laboratory, Department of Animal \& Poultry Sciences, Virginia Tech, \\ Blacksburg, VA 24061, USA \\ 2 Department of Animal Nutrition \& Nutritional Diseases, Faculty of Veterinary Medicine, Ankara University, \\ Ankara 06110, Turkey \\ 3 Department of Animal Production, Faculty of Agriculture, Cairo University, Giza 12613, Egypt \\ 4 PMI Nutritional Additives, Arden Hills, MN 55126, USA \\ * Correspondence: rdalloul@vt.edu
}

Received: 3 July 2019; Accepted: 8 August 2019; Published: 13 August 2019

\begin{abstract}
Necrotic enteritis, caused by Clostridium perfringens, is an enteric disease that leads to poor performance and increased mortality, resulting in significant economic losses in poultry production. This study evaluated the effects of a proprietary prebiotic, probiotic, and plant extract blend on performance of broilers during coccidiosis challenge leading to necrotic enteritis (NE). In total, 744 Cobb500 male broilers were randomly allocated to 3 treatments ( 8 replicates, 31 birds/pen) including, the negative control (NC) fed a basal diet; the positive control (PC) fed a basal diet with Virginiamycin; and the additive group fed basal diet with a blend of prebiotic, probiotic, and plant extract (BSN). A unique, naturally occurring NE model developed to mimic field conditions was implemented to challenge the birds. This model consists of spraying a concentrated commercial coccidiosis vaccine on litter and feed upon bird placement, which, in conjunction with the presence of C. perfringens spores in the environment, leads to the development of a NE outbreak one week post vaccine application. At the onset of $\mathrm{NE}$ on $\mathrm{d} 7$, three birds/pen were selected for scoring NE lesions. Body weight gain (BWG), feed intake (FI), and feed conversion ratio (FCR) were recorded on days $7,14,28$, and 42 . Carcass composition was assessed by dual energy X-ray absorptiometry (DXA) analysis on day 42. Dietary supplementation of BSN significantly $(p<0.05)$ improved FCR during starter and grower periods. Dietary treatments had no effect on NE lesions in the small intestine. DXA analysis revealed slightly higher lean content in BSN birds compared to NC. These results showed that dietary supplementation of the BSN blend significantly improved broilers performance during the early NE challenge phase, as well as in the grower period.
\end{abstract}

Keywords: Broiler; microbiota; necrotic enteritis; prebiotic; probiotic

\section{Introduction}

Necrotic enteritis (NE) is a small intestinal inflammatory disorder in modern poultry production systems that causes poor performance, increased mortality, reduced welfare of the birds, and contamination of food products for human consumption [1,2]. In addition, necrotic enteritis has an extensive economic impact on the poultry industry, with an estimated annual total loss of more than $\$ 6$ billion [3]. In poultry, both the clinical and subclinical causative agent of necrotic enteritis is Clostridium perfringens type $\mathrm{A}$, which is normally found to be less than $10^{2}$ to $10^{4} \mathrm{CFU} / \mathrm{g}$ digesta in the small intestine of healthy birds [1,4,5]. At low population levels, C. perfringens is nonpathogenic [6], 
even high numbers are not sufficient to produce necrotic enteritis lesions in the small intestine [7]. However, specific dietary and environmental conditions, such as diets high in undigestible, water soluble polysaccharides or fish meal, co-infection with Eimeria spp., or immunosuppressive viruses can promote development of necrotic enteritis in chickens [8,9]. Eimeria infection is commonly used as a predisposing factor in experimental conditions which contribute to massive proliferation of $C$. perfringens [10]. Eimeria-assisted induction of necrotic enteritis may be related to the epithelial damage of the intestine, which causes release of serum and several nutrients [11] or increased mucin production [2], which provides a favorable growth conditions for C. perfringens colonization and proliferation.

Recent studies revealed that removal of antibiotic growth promoters (AGPs) and anticoccidial drugs in poultry feeding has led to a decrease in animal performance, an increase in feed conversion ratio (FCR), and incidences of necrotic enteritis [12,13]. Increasing concerns of consumers over the possible antibiotic residues in animal products and the emergence of antibiotic resistant microbes have highlighted the growing need for alternative feed additives such as probiotics, prebiotics, organic acids, plant extracts (e.g., essential oils), and others that modulate the gastrointestinal microbiota to improve performance and disease resistance [14]. Alternative feed additives exhibit their positive effects by increasing the numbers of beneficial bacterial in intestinal tract and promoting gut health [15]. Colonization of the intestine with beneficial microbes not only prevents pathogenic bacteria-related intestinal disorders, but also improves intestinal maturation and integrity [16].

Enteric diseases in commercial poultry production cause significant economic losses and threaten public health via the potential contamination of food products derived from these animals [17]. Thus, there is an urgent need to develop rational, alternative, and integrated management strategies not only to control, but to prevent necrotic enteritis [10]. Based on the previously reported favorable effects of alternative feed additives, such as probiotics, prebiotics, and phytogenics (alone or in combinations), the current study was designed to evaluate the effects of a combined feed additive (containing probiotic bacteria, prebiotic polysaccharides, plant extracts) on performance and response of broiler chickens to an early coccidiosis challenge as a predisposing factor to induce necrotic enteritis.

\section{Results}

\subsection{Growth Performance}

The effects of dietary supplementation of a non-drug feed additive on broiler growth performance are presented in Table 1 (BWG, g/bird; FI, g/bird; FCR, g/g bird) and Figure 1 (Mortality, \%). No significant differences were observed in BWG during the starter (0-14 day) or overall trial period (0-42 day). However, birds in the BSN group tended to have higher $(p=0.051)$ BWG during the grower period (15-28 day). Antibiotic treatment (PC) increased the feed intake during the starter period as compared with NC and BSN groups $(p=0.005)$. Except for the starter period, no significant differences were observed between the groups in terms of FI during the entire study. The FCR was improved in birds fed the diet supplemented with a feed additive (BSN group) during the first week $(p=0.005)$, grower $(p=0.004)$, and finisher period ( $p=0.048)$. However, no significant difference in FCR was observed over the cumulative study period. Only the dietary antibiotic treatment significantly reduced the mortality rate during the starter $(p=0.002)$ and overall experimental $(p=0.006)$ periods. 
Table 1. Effects of dietary non-drug feed additive (BSN) on body weight gain ( $\mathrm{g} / \mathrm{bird}$ ), feed intake ( $\mathrm{g} / \mathrm{bird})$, and feed conversion ratio ( $\mathrm{g} / \mathrm{g}$ bird) of the experimental birds.

\begin{tabular}{lccccc}
\hline & \multicolumn{3}{c}{ Dietary Treatments } & \multicolumn{2}{c}{ Statistics } \\
\hline & NC & PC & BSN & SEM & $p$-Value \\
\hline $\mathbf{0}$ to 7 d & & & & & \\
BWG & 111.74 & 112.46 & 114.22 & 1.56 & 0.815 \\
FI & 145.57 & 151.21 & 139.14 & 2.10 & 0.056 \\
FCR & $1.303^{\text {ab }}$ & $1.350^{\mathrm{a}}$ & $1.223^{\mathrm{b}}$ & 0.02 & 0.005 \\
$\mathbf{0}$ to 14 d & & & & & \\
BWG & 311.27 & 325.79 & 314.44 & 5.92 & 0.596 \\
FI & $473.58^{\mathrm{b}}$ & $523.09^{\mathrm{a}}$ & $462.40^{\mathrm{b}}$ & 8.64 & 0.004 \\
FCR & 1.528 & 1.619 & 1.475 & 0.03 & 0.082 \\
$\mathbf{1 5}$ to $\mathbf{2 8} \mathbf{d}$ & & & & & \\
BWG & 771.53 & 874.56 & 906.39 & 24.17 & 0.051 \\
FI & 1451.3 & 1495.0 & 1483.6 & 27.94 & 0.817 \\
FCR & $1.906^{\mathrm{a}}$ & $1.711^{\mathrm{b}}$ & $1.643^{\mathrm{b}}$ & 0.04 & 0.004 \\
$\mathbf{1 5}$ to 42 d & & & & & \\
BWG & 1692.0 & 1902.7 & 1856.9 & 47.95 & 0.171 \\
FI & 3360.9 & 3603.1 & 3506.1 & 72.46 & 0.407 \\
FCR & $2.00^{\mathrm{a}}$ & $1.894^{\mathrm{b}}$ & $1.894^{\mathrm{b}}$ & 0.02 & 0.048 \\
$\mathbf{0}$ to 42 d & & & & & \\
BWG & 2003.3 & 2228.5 & 2171.3 & 52.16 & 0.191 \\
FI & 3834.4 & 4126.2 & 3968.6 & 77.15 & 0.316 \\
FCR & 1.925 & 1.854 & 1.833 & 0.02 & 0.102 \\
\hline
\end{tabular}

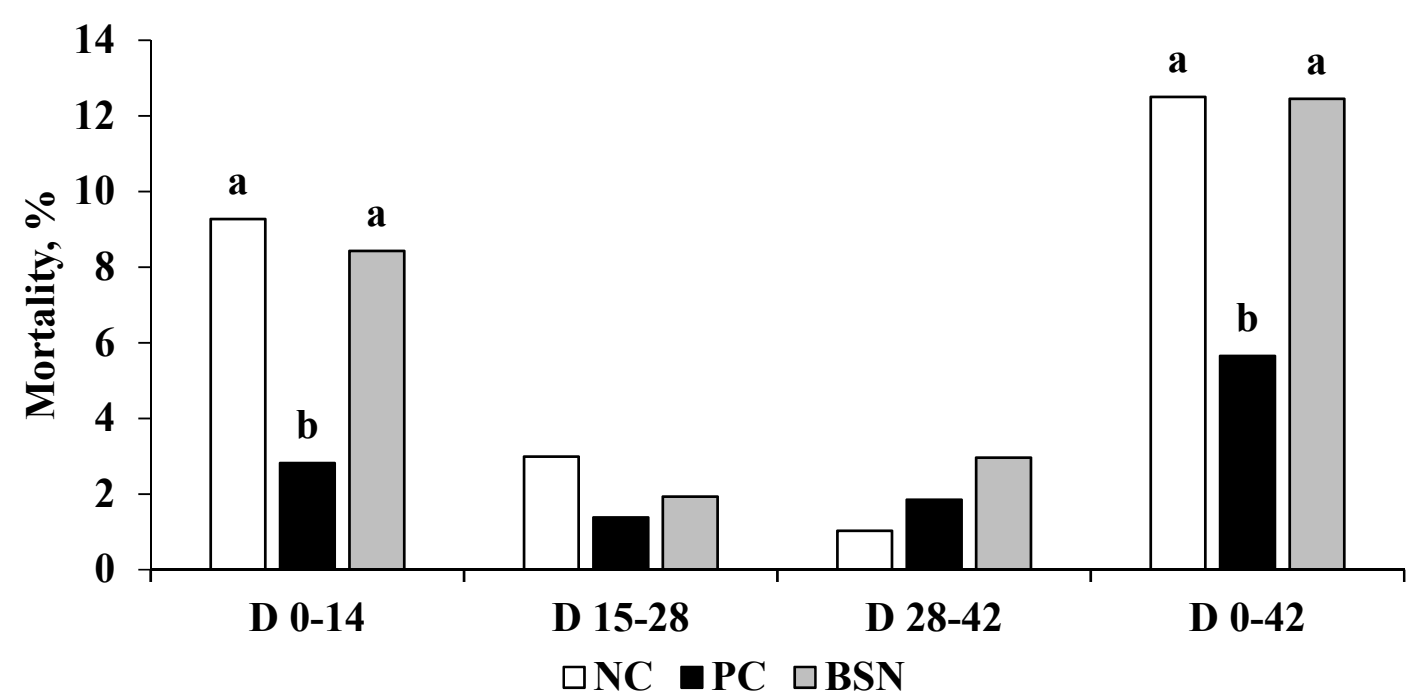

Figure 1. Effects of dietary non-drug feed additive (BSN) on mortality rate (\%) of the birds during starter, grower, finisher, and overall experimental periods. Bars with different letters $(a-b)$ differ significantly.

\subsection{Lesion Scores}

The effect of dietary supplementation of the non-drug feed additive on intestinal lesion scores is presented in Figure 2. No significant differences were observed in duodenal and ileal lesion scores between the treatments. However, jejunal lesion scores were minimal for all groups and tended to be lower in PC birds when compared with NC and BSN birds on day 7 ( $p=0.067)$. 


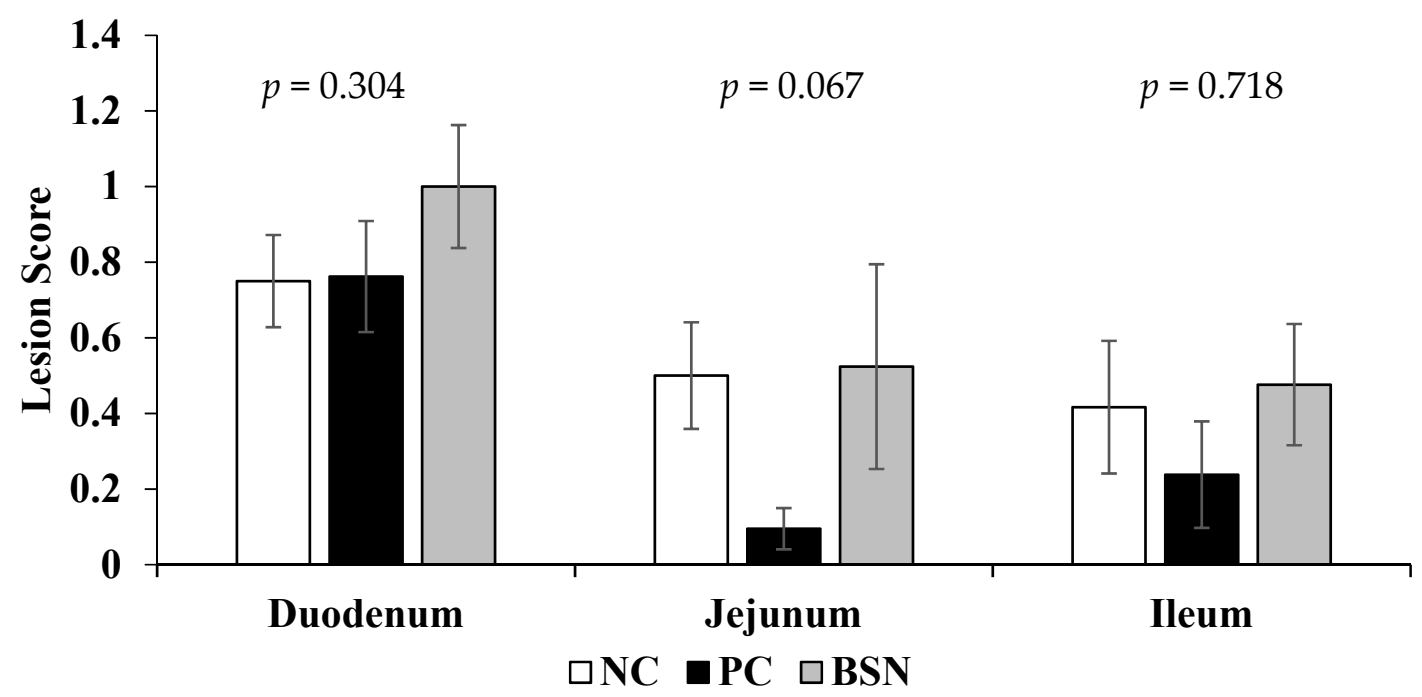

Figure 2. Effects of dietary non-drug feed additive (BSN) on lesion scores of duodenum, jejunum, and ileum on day 7 . Each bar represents the mean \pm SE values of 24 birds per treatment.

\subsection{Carcass and Body Composition}

The effects of dietary supplementation of non-drug feed additives on broiler body/carcass compositions (carcass weight, tissue weight, lean weight, fat weight, surface area of defeathered, whole carcass, tissue percentage, and bone mineral content) are shown in Figure 3A-C. No significant differences were observed between the treatment groups in terms of body/carcass composition on day $42(p>0.05)$.

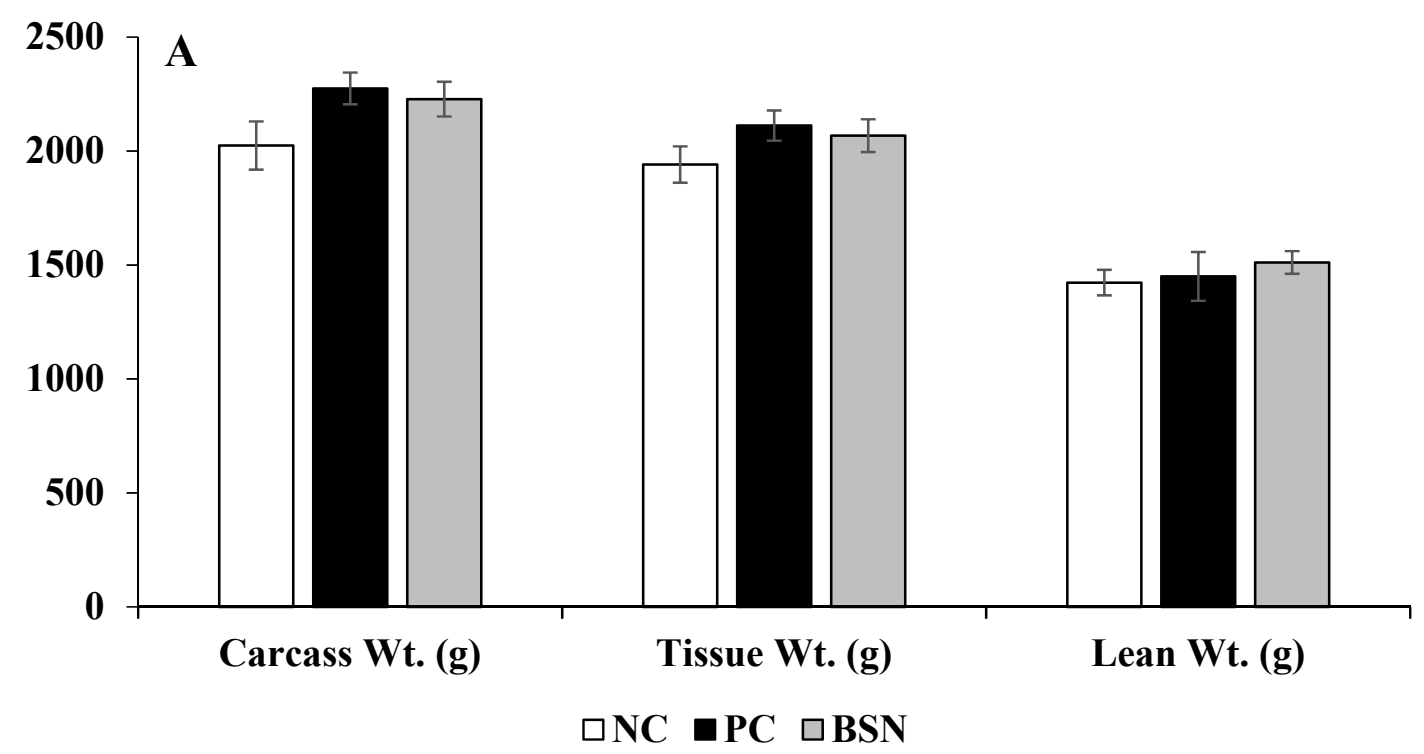

Figure 3. Cont. 

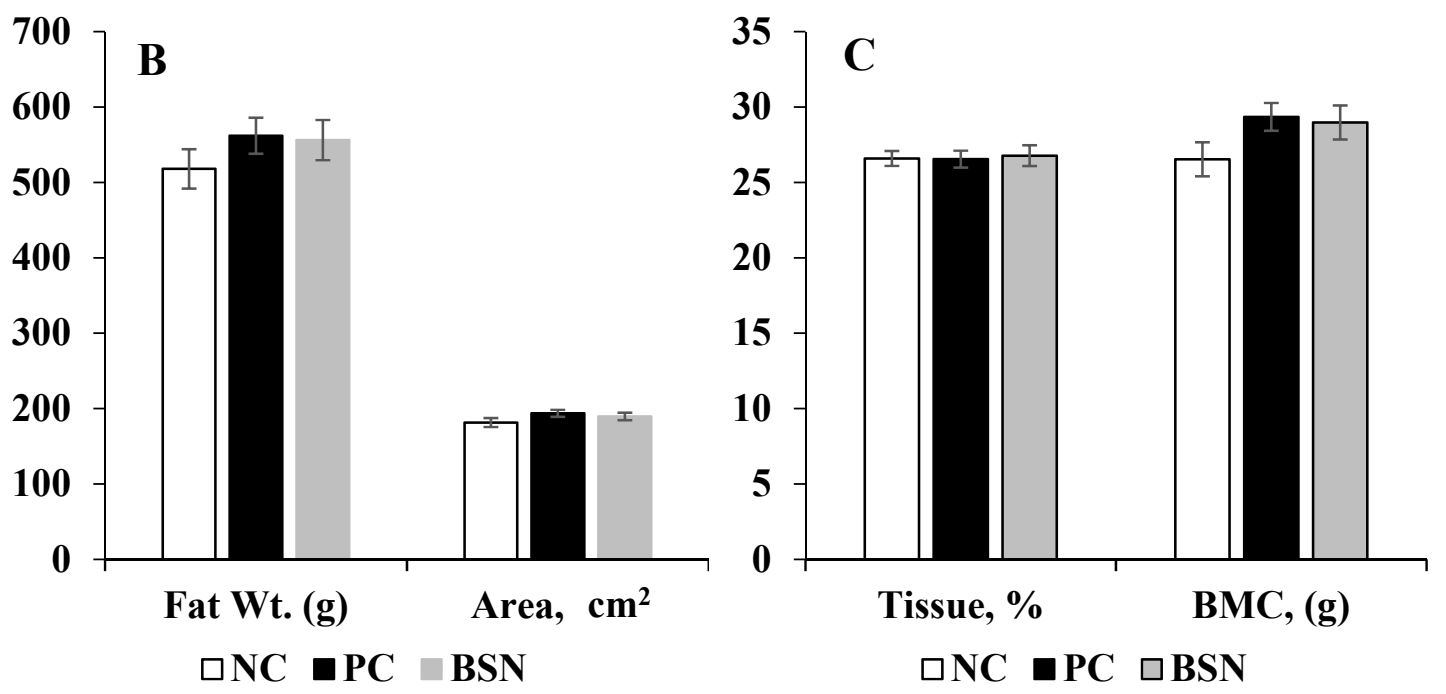

Figure 3. Effects of dietary non-drug feed additive (BSN) on body composition of broilers. (A) Carcass weight $(\mathrm{g})$, tissue weight $(\mathrm{g})$, and lean weight $(\mathrm{g})$. (B) Fat weight $(\mathrm{g})$ and body surface area $\left(\mathrm{cm}^{2}\right)$.

(C) Tissue (\%) and bone mineral content, BMC (g).

\section{Discussion}

Among the strategies to reduce the use of antibiotics in the broiler industry, dietary supplementation of non-drug feed additives is becoming an accepted alternative because of their beneficial effects against intestinal pathogens and improved bird performance and health without having the risk of drug residues or antibacterial resistance. In this context, the present study investigated the effect of a novel non-drug feed additive blend on broiler performance, body composition, and intestinal lesion scores of broiler chickens during a coccidiosis challenge leading to necrotic enteritis similar to field conditions. The more commonly published NE models involve first experimentally inoculating birds orally with a high dose of live Eimeria oocysts, followed with consecutive doses of $C$. perfringens bacteria. Conversely, the unique model presented herein relies on the bacterial spores present in the barn environment in addition to commensal C. perfringens under certain circumstances.

As an important intestinal infectious disease, necrotic enteritis is responsible for reduced performance and increased mortality in birds [18]. The presented results showed that dietary supplementation of a feed additive blend did not alleviate the growth suppression effect of NE during the starter period (days 0-14). However, birds fed a diet supplemented with BSN and AGP (Virginiamycin) had significantly better FCR during days 15-28 and days 15-42, which show that this feed additive promoted broiler performance similar to the AGP. However, dietary supplementation of BSN was significantly less effective than antibiotic treatment in reducing the mortality rate during the starter period (days 0-14) when the challenge was implemented. On the other hand, no significant mortality was observed among the treatment groups during days 15-28 and days 15-42. Dietary supplementations of certain feed additives, such as probiotics [19,20], prebiotics [21], essential oils [22], or mixed combination products [23], can be effective at reducing the negative effects of necrotic enteritis by modulating the beneficial intestinal microbiota and improving intestinal integrity and immune status of broiler chickens [18]. However, young chickens are more susceptible to intestinal infections since the protective microbial colonization patterns are unstable in early life stages [24]. Hence, the reason behind the reduced performance and increased mortality in BSN birds compared to the AGP during the starter period was likely due to the less-established microbiota early on during the first two weeks of the study. Moreover, even though we observed better FCR in BSN and AGP birds during the grower and finisher periods, numerically higher FCR in the AGP treatment and increased mortality in the BSN group during the starter period might be the reason for the non-significantly different overall corrected FCR (days 0-42). 
Broiler performance and intestinal lesion scores are important parameters used to evaluate the severity of enteric diseases such as coccidiosis [25] and NE [26]. Our results showed that dietary treatments had no effect on lesion scores in the duodenum and ileum. Conversely, jejunal lesion scores tended to be lower $(p=0.067)$ in PC birds compared to NC and BSN birds; albeit all three groups exhibited relatively minimal lesions. This outcome coincides with the observed higher feed intake and lower mortality in PC birds. Less intestinal damage is directly related to improved nutrient absorption and a better intestinal barrier against pathogens [25]. These results partially concur with the findings of M'Sadeq, Wu, Choct, Forder and Swick [15], who reported that antibiotic-treated birds had lower duodenal lesion scores than non-medicated and prebiotic-treated birds. Contradictory results are also evident in previous reports with regard to a decrease in intestinal NE lesion scores in broilers fed diets with feed additives [26,27]. The methodology employed in this study is quite unique, whereby the model does not involve inoculating C. perfringens bacteria, hence it is more comparable to field conditions. Conversely, in the reported studies, birds were directly inoculated towards the end of the starter period and lesion scores were evaluated during the grower period. These differences might be the underlying reason for the slightly higher lesion scores in the BSN group.

Dual-energy $X$-ray absorptiometry is used to estimate fat, fat-free soft tissue, and bone mineral components of the body [28]. For broiler studies, it is a useful tool for the in-depth understanding of bird performance [29]. Carcass, tissue, and lean weights showed similar patterns to overall BWG (days 0-42). However, there is limited reporting on the effects of such feed additives on broiler body composition during a pathogenic challenge. Although not significantly different, PC and BSN treatments had higher lean body composition than NC treatment, which is important from an industry perspective.

In conclusion, the present study demonstrated that supplementation of a feed additive blend significantly improved FCR during the grower and finisher periods when birds were subjected to a naturally occurring necrotic enteritis challenge. However, no significant differences were observed in overall performance, carcass composition, and lesion scores as compared with the control group. It should be noted that the severity of the infection or the supplementation level are important when alternative growth stimulators are applied. It would be useful to further assess the effects of this product on specific intestinal immune responses, tight junction proteins, intestinal microbiota, and short chain fatty acid composition under similar disease challenge conditions.

\section{Materials and Methods}

\subsection{Birds, Diet, and Management}

This project was approved and conducted under the guidelines of the Virginia Tech Institutional Animal Care and Use Committee (IACUC \#16-107; Approved July 8 2016). On day of hatch, 744 Cobb500 male broiler chicks were randomly allocated to 3 experimental dietary groups (8 replicate floor pens, 31 birds/pen) as follows: The negative control (NC) fed a corn/soybean basal diet; the positive control (PC) fed a basal diet with Virginiamycin; and the additive group (BSN) fed the basal diet supplemented with a feed additive $(567 \mathrm{~g} /$ ton for starter, $454 \mathrm{~g} /$ ton for grower, and $340 \mathrm{~g} /$ ton for finisher) consisting of essential oils (Yucca schidigera extract), prebiotic polysaccharides from food grade yeast extracts, glucans, mannans, quitines, and galactans, plus saponins obtained from the Yucca schidigera plant and a combination of probiotic Bacillus bacteria (B. subtilis, B. licheniformis, B. coagulans), delivering $1.32 \times 10^{11} \mathrm{CFU} / \mathrm{kg}$ of total microbial count. Chicks had ad libitum access to water and a non-medicated corn/soy-based crumble (starter days 1-14) or pellet form diets (grower days 15-28 and finisher days 29-42). The corn/soybean basal diet (Table 2) was formulated to meet or exceed the nutrient requirements for broilers as recommended by the National Research Council (NRC) [30]. The temperature was maintained at $34^{\circ} \mathrm{C}$ from day 1 to day 7 post-hatch and was progressively reduced to $27^{\circ} \mathrm{C}$ on day $14,21^{\circ} \mathrm{C}$ on day 28 , and $18^{\circ} \mathrm{C}$ on day 42 . The light cycle was $20 \mathrm{~h}$ light and $4 \mathrm{~h}$ dark. 
Table 2. Composition and calculated analyses of basal diet.

\begin{tabular}{lccc}
\hline Ingredient, \% & Starter (0-14 d) & Grower (15-28 d) & Finisher (29-42 d) \\
\hline Corn & 60.14 & 65.34 & 69.91 \\
Soybean meal (48\%) & 22.41 & 16.43 & 10.76 \\
Distiller's grain & 7.00 & 8.00 & 9.00 \\
Poultry by-product meal & 5.00 & 5.00 & 4.00 \\
Grease (yellow) & 1.90 & 2.12 & 2.76 \\
Limestone & 0.58 & 0.54 & 0.70 \\
Dicalcium phosphate & 1.15 & 0.90 & 0.78 \\
Salt & 0.27 & 0.17 & 0.16 \\
DL-Methionine & 0.18 & 0.30 & 0.80 \\
L-Lysine & 0.63 & 0.60 & 0.80 \\
L-Threonine & 0.10 & 0.10 & 0.10 \\
Vit. \& Min. Premix & 0.63 & 0.50 & 0.50 \\
(Big Spring Mills) & & 100.00 & 100.00 \\
Total & 100.00 & & \\
Calculated nutrient level & & 3,102 & 3,157 \\
ME, kcal/kg & 3,036 & 19.00 & 17.00 \\
CP, \% & 21.00 & 0.80 & 0.76 \\
Ca, \% & 0.90 & 0.40 & 0.35 \\
Available P, \% & 0.45 & 0.64 & 0.57 \\
Total P, \% & 0.71 & 1.33 & 1.32 \\
Lysine, \% & 1.50 & 0.60 & 1.06 \\
Methionine, \% & 0.50 & 0.81 & 0.71 \\
Threonin, \% & 0.89 & 0.19 & 0.16 \\
Tryptophan, \% & 0.22 & & \\
\hline Provided per kilogram & & & \\
\hline
\end{tabular}

${ }^{1}$ Provided per kilogram of diet: Cobalt (min), 30 ppm; copper (min), 4.75 ppm; iodine (min), 1.18 ppm; iron (min), 59.40 ppm; manganese (min), 75.50 ppm; zinc (min), 57.20 ppm; vitamin A (min), 7749.28 IU; vitamin $\mathrm{D}_{3}$ (min), 2596.01I CU; vitamin E (min), $1.94 \mathrm{IU}$; vitamin $\mathrm{B}_{12}(\mathrm{~min}), 0.01 \mathrm{mg}$; menadione (min), $1.36 \mathrm{mg}$; riboflavin (min), $4.84 \mathrm{mg}$; D-pantothenic acid (min), $7.13 \mathrm{mg}$; niacin (min), $23.25 \mathrm{mg}$; choline (min), $448.43 \mathrm{mg}$.

\subsection{Necrotic Enteritis Challenge and Lesion Scoring}

Upon placement, all birds were indirectly challenged with a coccidia vaccine as a predisposing factor to NE. This is a unique, naturally occurring NE model developed on our research farm which consists of spraying a concentrated commercial coccidiosis vaccine on litter and feed upon bird placement, which, in conjunction with the presence of $C$. perfringens spores in the barn environment, leads to the development of a NE outbreak one week post vaccine application. For this trial, we applied the Coccivac ${ }^{\circledR}$-B52 vaccine (containing live oocysts of Eimeria acervulina, E. maxima, E. maxima MFP, E. mivati, and E. tenella; Merck Animal Health). Three birds per pen were selected (based on average pen weight) on day 7 (based on NE peak outbreak), individually weighed, and sacrificed. Intestinal NE lesion scores were assessed for the afflicted sections of the small intestine (duodenum, jejunum, and ileum), per standard protocols by personnel blinded to the treatments using the following scale: $\mathrm{A}$ value of $0=$ no gross lesions, $1=$ thin-walled or friable, $2=$ focal necrosis or ulceration, $3=$ multifocal coalescing areas (large patches) of necrosis, and $4=$ severe extensive necrosis.

\subsection{Growth Performance}

Standard performance parameters including body weight (BW), body weight gain (BWG), and feed intake (FI) were recorded on days $7,14,28$, and 42 on a bird per pen basis. Daily mortality and body weight of each dead bird were recorded and feed conversion ratio (FCR) was corrected by accounting for the BW of each dead bird.

\subsection{Carcass and Body Composition}

On day 42 , two birds per pen were individually wing-banded, sacrificed by cervical dislocation, and subsequently defeathered and stored at $-20{ }^{\circ} \mathrm{C}$ until further analysis. Carcasses were thawed 
and scanned by dual energy X-ray absorptiometry (DXA) using the GE Healthcare Lunar Prodigy Advance, System ID PA+130,744 (General Electric, Madison, WI, USA). After scanning, the Prodigy Small Animal Software was used to quantify and calculate whole, defeathered carcass weight (g), lean weight $(\mathrm{g})$, fat weight $(\mathrm{g})$, tissue weight (lean weight, $\mathrm{g}+$ fat weight, $\mathrm{g})$, and carcass surface area $\left(\mathrm{cm}^{2}\right)$, tissue $(\%)$, and bone mineral content, BMC (g).

\subsection{Statistical Analysis}

Performance and carcass composition data were subjected to a one-way analysis of variance (ANOVA) using the SAS program (SAS, 2004). When significant differences were noted, Tukey's test was used to compare separated means. The influence of the feed additive on NE lesion scores was performed with the non-parametric Kruskal-Wallis test. Mortality rates were compared using a Chi-square test. Statistical differences were considered significant at $p \leq 0.05$.

Author Contributions: A.C., I.I.O., and M.B.W. conducted the study and supervised all analyses; A.C. wrote the paper; N.P.E. and T.P.K. contributed to research design and manuscript revisions; R.A.D. was the principal investigator involved in every aspect of this study. All authors read and approved the final manuscript.

Funding: This work was supported in part USDA National Institute of Food and Agriculture Hatch funds to the Virginia Agricultural Experiment Station and APC support from the Virginia Tech OASF.

Acknowledgments: Ali Calik was a recipient of the postdoctoral fellowship of the Scientific and Technological Research Council of Turkey (TUBITAK).

Conflicts of Interest: The authors declare no conflict of interest.

\section{References}

1. Timbermont, L.; Lanckriet, A.; Gholamiandehkordi, A.R.; Pasmans, F.; Martel, A.; Haesebrouck, F.; Ducatelle, R.; Van Immerseel, F. Origin of Clostridium perfringens isolates determines the ability to induce necrotic enteritis in broilers. Comp. Immunol. Microbiol. Infect. Dis. 2009, 32, 503-512. [CrossRef]

2. Collier, C.T.; Hofacre, C.L.; Payne, A.M.; Anderson, D.B.; Kaiser, P.; Mackie, R.I.; Gaskins, H.R. Coccidia-induced mucogenesis promotes the onset of necrotic enteritis by supporting Clostridium perfringens growth. Vet. Immunol. Immunopathol. 2008, 122, 104-115. [CrossRef]

3. Wade, B.; Keyburn, A.L.; Seemann, T.; Rood, J.I.; Moore, R.J. Binding of Clostridium perfringens to collagen correlates with the ability to cause necrotic enteritis in chickens. Vet. Microbiol. 2015, 180, 299-303. [CrossRef]

4. Shojadoost, B.; Vince, A.R.; Prescott, J.F. The successful experimental induction of necrotic enteritis in chickens by Clostridium perfringens: A critical review. Vet. Res. 2012, 43, 74. [CrossRef]

5. Kondo, F. In vitro lecithinase activity and sensitivity to 22 antimicrobial agents of Clostridium perfringens isolated from necrotic enteritis of broiler chickens. Res. Vet. Sci. 1988, 45, 337-340. [CrossRef]

6. McDevitt, R.; Brooker, J.; Acamovic, T.; Sparks, N. Necrotic enteritis; a continuing challenge for the poultry industry. World's Poult. Sci. J. 2006, 62, 221-247. [CrossRef]

7. Cooper, K.K.; Songer, J.G. Necrotic enteritis in chickens: A paradigm of enteric infection by Clostridium perfringens type A. Anaerobe 2009, 15, 55-60. [CrossRef]

8. Timbermont, L.; Haesebrouck, F.; Ducatelle, R.; Van Immerseel, F. Necrotic enteritis in broilers: An updated review on the pathogenesis. Avian Pathol. 2011, 40, 341-347. [CrossRef]

9. Lee, K.W.; Lillehoj, H.S.; Jeong, W.; Jeoung, H.Y.; An, D.J. Avian necrotic enteritis: Experimental models, host immunity, pathogenesis, risk factors, and vaccine development. Poult. Sci. 2011, 90, 1381-1390. [CrossRef]

10. Williams, R.B. Intercurrent coccidiosis and necrotic enteritis of chickens: Rational, integrated disease management by maintenance of gut integrity. Avian Pathol. 2005, 34, 159-180. [CrossRef]

11. Van Immerseel, F.; Rood, J.I.; Moore, R.J.; Titball, R.W. Rethinking our understanding of the pathogenesis of necrotic enteritis in chickens. Trends Microbiol. 2009, 17, 32-36. [CrossRef]

12. Dibner, J.J.; Richards, J.D. Antibiotic growth promoters in agriculture: History and mode of action. Poult. Sci. 2005, 84, 634-643. [CrossRef]

13. Gaucher, M.L.; Quessy, S.; Letellier, A.; Arsenault, J.; Boulianne, M. Impact of a drug-free program on broiler chicken growth performances, gut health, Clostridium perfringens and Campylobacter jejuni occurrences at the farm level. Poult. Sci. 2015, 94, 1791-1801. [CrossRef] 
14. Calik, A.; Ergun, A. Effect of lactulose supplementation on growth performance, intestinal histomorphology, cecal microbial population, and short-chain fatty acid composition of broiler chickens. Poult. Sci. 2015, 94, 2173-2182. [CrossRef]

15. M'Sadeq, S.A.; Wu, S.-B.; Choct, M.; Forder, R.; Swick, R.A. Use of yeast cell wall extract as a tool to reduce the impact of necrotic enteritis in broilers. Poult. Sci. 2015, 94, 898-905. [CrossRef]

16. Lan, Y.; Verstegen, M.; Tamminga, S.; Williams, B. The role of the commensal gut microbial community in broiler chickens. World's Poult. Sci. J. 2005, 61, 95-104. [CrossRef]

17. Lee, K.-W.; Lillehoj, H.S.; Jang, S.I.; Li, G.; Lee, S.-H.; Lillehoj, E.P.; Siragusa, G.R. Effect of Bacillus-based direct-fed microbials on Eimeria maxima infection in broiler chickens. Comp. Immunol. Microbiol. Infect. Dis. 2010, 33, e105-e110. [CrossRef]

18. Caly, D.L.; D'Inca, R.; Auclair, E.; Drider, D. Alternatives to Antibiotics to Prevent Necrotic Enteritis in Broiler Chickens: A Microbiologist's Perspective. Front. Microbiol. 2015, 6, 1336. [CrossRef]

19. Whelan, R.A.; Doranalli, K.; Rinttilä, T.; Vienola, K.; Jurgens, G.; Apajalahti, J. The impact of Bacillus subtilis DSM 32315 on the pathology, performance, and intestinal microbiome of broiler chickens in a necrotic enteritis challenge. Poult. Sci. 2018. [CrossRef]

20. Wang, H.; Ni, X.; Qing, X.; Liu, L.; Lai, J.; Khalique, A.; Li, G.; Pan, K.; Jing, B.; Zeng, D. Probiotic enhanced intestinal immunity in broilers against subclinical necrotic enteritis. Front. Immunol. 2017, 8, 1592. [CrossRef]

21. Keerqin, C.; Morgan, N.K.; Wu, S.B.; Swick, R.A.; Choct, M. Dietary inclusion of arabinoxylo-oligosaccharides in response to broilers challenged with subclinical necrotic enteritis. Br. Poult. Sci. 2017, 58, 418-424. [CrossRef]

22. Yin, D.; Du, E.; Yuan, J.; Gao, J.; Wang, Y.; Aggrey, S.E.; Guo, Y. Supplemental thymol and carvacrol increases ileum Lactobacillus population and reduces effect of necrotic enteritis caused by Clostridium perfringes in chickens. Sci. Rep. 2017, 7, 7334. [CrossRef]

23. Bortoluzzi, C.; Rothrock, M.J.; Vieira, B.S.; Mallo, J.J.; Puyalto, M.; Hofacre, C.; Applegate, T.J. Supplementation of protected sodium butyrate alone or in combination with essential oils modulated the cecal microbiota of broiler chickens challenged with Coccidia and Clostridium perfringens. Front. Sustain. Food Syst. 2018, 2. [CrossRef]

24. Gaggia, F.; Mattarelli, P.; Biavati, B. Probiotics and prebiotics in animal feeding for safe food production. Int. J. Food Microbiol. 2010, 141, S15-S28. [CrossRef]

25. Ritzi, M.M.; Abdelrahman, W.; van-Heerden, K.; Mohnl, M.; Barrett, N.W.; Dalloul, R.A. Combination of probiotics and coccidiosis vaccine enhances protection against an Eimeria challenge. Vet. Res. 2016, 47, 111. [CrossRef]

26. Jayaraman, S.; Thangavel, G.; Kurian, H.; Mani, R.; Mukkalil, R.; Chirakkal, H. Bacillus subtilis PB6 improves intestinal health of broiler chickens challenged with Clostridium perfringens-induced necrotic enteritis. Poult. Sci. 2013, 92, 370-374. [CrossRef]

27. Tactacan, G.; Schmidt, J.; Miille, M.; Jimenez, D. A Bacillus subtilis (QST 713) spore-based probiotic for necrotic enteritis control in broiler chickens. J. Appl. Poult. Res. 2013, 22, 825-831. [CrossRef]

28. Laskey, M.A. Dual-energy X-ray absorptiometry and body composition. Nutrition 1996, 12, 45-51. [CrossRef]

29. Ott, C.; Omara, I.; Persia, M.; Dalloul, R. The impact of $\beta$-glucans on performance and response of broiler chickens during a coccidiosis challenge. Poult. Sci. 2018, 97, 2713-2721. [CrossRef]

30. NRC. Nutrient Requirements of Poultry, 9th ed.; National Academies Press: Washington, DC, USA, 1994.

(C) 2019 by the authors. Licensee MDPI, Basel, Switzerland. This article is an open access article distributed under the terms and conditions of the Creative Commons Attribution (CC BY) license (http://creativecommons.org/licenses/by/4.0/). 